\title{
Serum tumor necrosis factor-like weak inducer of apoptosis levels are elevated in schizophrenia
}

\author{
Faruk Kiliç, ${ }^{1}$ (iD Ümit Işik, ${ }^{2}$ iD Ayşe Usta, ${ }^{1}$ (iD Arif Demirdaş ${ }^{1}$ iD \\ ${ }^{1}$ Department of Psychiatry, Süleyman Demirel University Medicine Faculty, Isparta, Turkey. ${ }^{2}$ Department of Child and Adolescent Psychiatry, \\ Süleyman Demirel University Medicine Faculty, Isparta, Turkey.
}

\begin{abstract}
Objective: The purpose of this study was to assess serum Tumor necrosis factor-like weak inducer of apoptosis (TWEAK) concentrations to determine whether changes in patients with schizophrenia could have etiopathogenetic importance. Since very little research has addressed the connection between the inflammatory marker TWEAK and schizophrenia, we wanted to examine alterations of TWEAK and investigate the possible correlation between clinical symptomatology and serum concentrations.

Methods: A total of 45 schizophrenia patients and 40 healthy controls were included in this study. The Positive Symptom Assessment scale and the Negative Symptom Assessment scale were administered to determine symptom severity. Venous blood samples were collected and serum TWEAK levels were measured.

Results: Serum TWEAK levels were significantly higher in the schizophrenia group than the control group, independently of potential confounders, including sex, age, body mass index and smoking status. Conclusion: The results indicate that TWEAK is elevated in schizophrenia patients, which could deepen our understanding of the role of inflammation in the pathogenesis of schizophrenia.
\end{abstract}

Keywords: Neuroinflammation; serum level; schizophrenia; TWEAK

\section{Introduction}

Schizophrenia, a chronic mental disorder affecting roughly $1 \%$ of the world population, is characterized by distortion of thought, language, emotion, perception, and behavior. ${ }^{1,2}$ It is a serious burden for the patient and causes significant expense for society. ${ }^{3}$ Since the etiology of schizophrenia is still unclear, most treatments have focused on symptom reduction by blocking the dopamine system. ${ }^{4}$ Nevertheless, it is likely that a better understanding of the molecular mechanisms underlying schizophrenia symptoms will be necessary to enhance current drug treatments and develop new and effective therapies, as has recently been emphasized. ${ }^{5}$

Over the previous few years, a number of clinical and molecular studies have investigated the role of inflammatory impairment in schizophrenia and how to target these pathways as an add-on to current therapies. ${ }^{6-8}$ Schizophrenia is associated with poor communication between the central nervous system and the immune system. ${ }^{9}$ Numerous studies have discovered that blood levels of inflammatory cytokines are increased in individuals with schizophrenia. ${ }^{10,11}$ Among them, the cytokine tumor necrosis factor (TNF)-like weak inducer of apoptosis (TWEAK) is a transmembrane protein belonging to the TNF ligand family whose transcripts are found in many tissues,

Correspondence: Faruk Kilic, Assistant Professor, Department of Psychiatry, Süleyman Demirel University Medicine Faculty, 32260, Isparta, Turkey.

E-mail: drfarukk33@ hotmail.com

Submitted Mar 09 2020, accepted Apr 02 2020, Epub Aug 072020 including the brain. ${ }^{12}$ TWEAK can be released and act as a soluble cytokine. ${ }^{13}$ The biological impact of TWEAK includes tissue repair-related procedures, such as cell proliferation, cell migration, and angiogenesis. ${ }^{14,15}$ TWEAK reduces the shift from innate to adaptive $T$ helper 1 immune response, suppressing pro-inflammatory cytokines such as interleukin-12 and interferon-gamma and counterbalancing TNF-alpha activity. ${ }^{16}$

Increased TWEAK concentrations have been correlated with autoimmune diseases, such as systemic lupus erythematosus, rheumatoid arthritis, and psoriasis. ${ }^{17-19}$ Studies have also shown that TWEAK contributes to neurological conditions, such as multiple sclerosis, Parkinson's disease and experimental autoimmune encephalitis. ${ }^{20-22}$ In addition, TWEAK has been studied in connection with psychiatric disorders, such as major depression, bipolar disorder, cocaine dependence. ${ }^{23-26}$ To the best of our knowledge, only one study has investigated TWEAK levels in schizophrenia. ${ }^{27}$ Given the importance of neuroinflammation changes in schizophrenia, biomarkers of persistent inflammation are needed, especially in view of therapeutics.

Thus, the present study aimed to determine whether serum TWEAK could be a useful biomarker of neuroinflammation in patients with schizophrenia. In this context, we examined alterations of the inflammatory marker

How to cite this article: Kiliç F, Işık Ü, Usta A, Demirdaş A. Serum tumor necrosis factor-like weak inducer of apoptosis levels are elevated in schizophrenia. Braz J Psychiatry. 2021;43:242-246. http://dx.doi.org/10.1590/1516-4446-2020-0950 
TWEAK in schizophrenia and investigated possible correlations between serum TWEAK concentrations and clinical symptomatology.

\section{Methods}

\section{Subjects}

The sample consisted of 45 patients (12 women and 33 men) who were diagnosed with schizophrenia in accordance with the DSM-IV-TR at the Department of Psychiatry of the Suleyman Demirel University School of Medicine. The schizophrenia diagnosis was based on one senior psychiatrist's ongoing clinical interviews. There is significant heterogeneity in the existing research on inflammatory cytokines in schizophrenia, such as the use of patients in different phases of disorder (including those who did not suffer from acute psychotic episodes). ${ }^{28}$ The patients included in the present study had been using antipsychotic drugs regularly for the past year. In addition, patients who used only psychotropics were included. The control group consisted of 40 healthy participants (14 women and 26 men) matched by age and sex from among the hospital staff who had no history of mental disorder and were not on any medication. None of the respondents had a history of serious physical illness, including cardiac illness, chronic renal illness, cancer, neurological disorders, chronic infections, or immunological illnesses.

\section{Clinical assessment}

The Scale for the Assessment of Positive Symptoms (SAPS) and the Scale for the Assessment of Negative Symptoms (SANS) were used to evaluate schizophrenia symptoms. Andreasen developed the SAPS to assess the level, distribution, and severity of change in positive schizophrenia symptoms and the SANS to assess the level, distribution, and severity change in negative schizophrenia symptoms. ${ }^{29}$ Erkoç et al. studied the validity-reliability of Turkish version of both scales. ${ }^{30,31}$

\section{Determination of serum TWEAK levels}

Venous blood specimens from the left forearm vein were gathered between 8 am and 9 am after overnight fasting. To remove the plasma, the blood samples were centrifuged for 10 minutes at $3,000 \mathrm{rpm}$ at $4{ }^{\circ} \mathrm{C}$. The serum specimens were stored at $-80{ }^{\circ} \mathrm{C}$ until analysis. An Elabscience Instant ELISA kit (E-EL-H3651) was used according to manufacturer instructions to measure serum TWEAK concentrations. Serum TWEAK levels were recorded in $\mathrm{pg} / \mathrm{mL}$.

\section{Statistical analysis}

The data were analyzed in SPSS version 20 . The Kolmogorov-Smirnov test was used to determine whether the variables were normally distributed. The data are shown as mean and standard deviation and were evaluated using descriptive analysis. Relationships between categorical data were evaluated with the chi-square test. The psychological outcomes and biochemical parameters of the patient and control groups were compared with Student's $t$-test or the Mann-Whitney $U$ test according to distribution. To analyze the correlations between clinical features and serum TWEAK levels, the Spearman rank correlation coefficient was used. TWEAK levels were log-transformed and used in analysis of covariance (ANCOVA) to compare between-group mean differences, using age, sex, body mass index (BMI) and smoking status as covariate factors. P-values $<0.05$ (two-tailed) were considered significant.

\section{Ethics statement}

All participants provided written informed consent prior to participation. The study was conducted according to Helsinki Declaration principles and was approved by the local ethics committee.

\section{Results}

The study group included 45 patients (12 women and 33 men) with a mean age of $37.4 \pm 9.8$ years, while the control group $(n=40)$ included 14 women and 26 men with a mean age of $37.9 \pm 6.9$ years. There were no significant age and sex differences between patients with schizophrenia and healthy controls. Smoking rates were $68.9 \%$ $(n=31)$ in the schizophrenia group and $42.5 \%(n=17)$ in the control group, a significant difference $\left(\chi^{2}=5.999\right.$, $\mathrm{p}=0.014)$. There was also a statistically significant difference between the groups for BMI $(29.8 \pm 6.2$ in the patient group, and $25.8 \pm 3.5$ in the control group) ( $p<0.001)$. Table 1 summarizes the demographic characteristics of the participants and the clinical information of the patient group. Mean illness duration was $13.1 \pm 9.7$ years in the schizophrenia patients. The mean SANS and SAPS scores were $49.4 \pm 28.6$ and $22.6 \pm 24.0$, respectively, in the patient group. The patients were on the following antipsychotic drug regimens: single antipsychotic $(n=18)$, multiple antipsychotics $(n=17)$, and oral or depot atypical antipsychotics $(n=10)$. The mean duration of medication use in the patient group was $10.6 \pm 7.6$ years. Thirteen patients had attempted suicide (28.9\%).

The mean serum TWEAK levels were $2.34 \pm 1.00 \mathrm{pg} /$ $\mathrm{mL}$ in the schizophrenia group and $2.00 \pm 0.74 \mathrm{pg} / \mathrm{mL}$ in the control group. Serum TWEAK levels were significantly higher in the schizophrenia group than the control group $(z=-2.316, p=0.021)$. In ANCOVA, the difference in TWEAK levels remained significant even after controlling for age, sex, BMI and smoking status $\left(F_{1,79}=5.171\right.$, $\eta_{p}^{2}=0.061, p=0.026$ ) (Table 1$)$. In addition, correlations were calculated between serum TWEAK concentrations and age, BMI, illness duration, and clinical variables, such as SAPS and SANS scores. There was no significant correlation between serum TWEAK concentrations, total SAPS and SANS scores, and other parameters $(p>0.05)$. We also tested TWEAK levels separately for male and female patients and male and female controls, and no difference was found $(z=-1.817, p=0.069$ for male; $z=-1.389, p=0.176$ for female). 
Table 1 Demographic and clinical characteristics of patients with schizophrenia and controls

\begin{tabular}{|c|c|c|c|c|}
\hline & Schizophrenia $(n=45)$ & Controls $(n=40)$ & $t / z / \chi^{2}$ & $\mathrm{p}$-value \\
\hline Age (years) & $37.4 \pm 9.8$ & $37.9 \pm 6.9$ & $-0.224 *$ & 0.823 \\
\hline Sex (male/female) & $33 / 12$ & $26 / 14$ & $0.693^{\dagger}$ & 0.405 \\
\hline Smoking (smoker/nonsmoker) & $31 / 14$ & $17 / 23$ & $5.9999^{\dagger}$ & 0.014 \\
\hline BMI & $29.8 \pm 6.2$ & $25.8 \pm 3.5$ & 3.684 & $<0.001$ \\
\hline TWEAK $(\mathrm{pg} / \mathrm{mL})^{\ddagger}$ & $2.34 \pm 1.00$ & $2.00 \pm 0.74$ & $-2.316^{\S}$ & 0.021 \\
\hline History of suicide attempt (yes/no) & 13/32 & & & \\
\hline Duration of illness (years) & $13.1 \pm 9.7$ & & & \\
\hline Duration of drug use (years) & $10.6 \pm 7.6$ & & & \\
\hline Number of hospitalizations & $2.1 \pm 2.4$ & & & \\
\hline SAPS & $22.6 \pm 24.0$ & & & \\
\hline SANS & $49.4 \pm 28.6$ & & & \\
\hline
\end{tabular}

$\mathrm{BMI}=$ body mass index; SANS = Scale for the Assessment of Negative Symptoms; SAPS = Scale for the Assessment of Positive Symptoms.

* Student's t-test.

'Chi-square test.

* Log-transformed variables, analysis of covariance was used after adjustment for age, sex, BMI and smoking status percentile for comparisons between two groups $\left(F_{1,79}=5.171, p=0.026, \eta_{p}^{2}=0.061\right)$.

${ }^{\S}$ Mann-Whitney $U$ test.

Bold type denotes statistical significance.

\section{Discussion}

To the best of our knowledge, this is the second study to have been conducted on TWEAK levels in patients with schizophrenia. The major finding of our study is that serum TWEAK levels were significantly higher in patients with schizophrenia than in controls. In ANCOVA, the difference in TWEAK levels remained significant even after controlling for age, sex, BMI, and smoking status. However, there was no significant correlation between serum TWEAK concentrations and the severity of schizophrenia symptoms. These findings suggest that serum TWEAK concentrations may be related to schizophrenia etiopathogenesis, regardless of symptom severity.

In recent years, literature on the relationship between inflammatory cytokines and schizophrenia has been expanding. High concentrations of several types of inflammatory mediators have been found in the serum of schizophrenia patients, such as IL-1, IL-1 1 , IL-6, and TNF- $\alpha,{ }^{10,11}$ and neuroinflammation may contribute to the pathogenesis of schizophrenia. ${ }^{32}$ TWEAK, another cytokine, is a transmembrane protein belonging to the TNF ligand family whose transcripts are present in many tissues, including the brain. ${ }^{33}$ To date, circulating TWEAK concentrations have only been investigated in mental disorders such as major depression, bipolar disorder and crack cocaine dependence. $23-26$ The major depression study found that serum TWEAK levels were lower in both unmedicated and medicated depression patients than healthy controls. ${ }^{26}$ Regarding bipolar disorder, Barbosa et al. ${ }^{23}$ found a link between higher TWEAK concentrations and bipolar disorder, concluding that TWEAK may play a role in the pathophysiology of bipolar disorder. However, Cingi et al., ${ }^{24}$ reported significantly lower TWEAK concentrations in bipolar disorder patients in both a manic episode and a remission group than in controls. The authors pointed out that TWEAK-related immune response might be impaired in bipolar disorder, and this impairment seems not to be related to manic episodes.

Only one study has investigated TWEAK levels in schizophrenia. ${ }^{27}$ Unlike in our study, Tatlidil Yaylaci et al. ${ }^{27}$ found no significant differences in serum TWEAK levels in patients with schizophrenia compared to healthy controls, although they found that TWEAK levels in male patients were significantly lower than in male controls. It is stated in the literature that some confounding factors, such as age, smoking, BMI, and gender, may affect the inflammatory system. ${ }^{34-36}$ In our study, ANCOVA revealed higher serum TWEAK levels in schizophrenia patients, independently of confounding factors such as age, sex, BMl and smoking status. The high TWEAK levels found in schizophrenia patients suggest that TWEAK may play an important role in the etiology of schizophrenia. Thus, it is a significant finding that patients with schizophrenia had higher serum TWEAK concentrations than controls.

We analyzed the relationship between TWEAK serum levels and SANS and SAPS scores and found no correlation between them and, thus, symptom severity. Our results are congruent with the aforementioned schizophrenia study, which also found no correlation between TWEAK levels and symptom severity. Although we found no correlation between TWEAK, which is a proinflammatory cytokine, and schizophrenia symptoms, a recent meta-analysis indicated that the severity of psychotic symptoms was associated with cytokine abnormalities, especially pro-inflammatory cytokine levels. ${ }^{37}$ Therefore, the correlation between TWEAK concentrations and symptom severity should be clarified in future research.

Moreover, other studies have indicated that TWEAK may play a part in regulating the permeability of the bloodbrain barrier (BBB). ${ }^{38,39}$ The BBB is a physical and metabolic membrane separating the central nervous system from the circulatory system. Increased permeability of the BBB is an early and critical event in the development and evolution of inflammatory brain diseases. ${ }^{40}$ It is well known that TWEAK targets endothelial cells and astrocytes, which are two of the main cellular components of the BBB. ${ }^{41}$ It has also been shown that TWEAK disrupts the architecture of the BBB when injected into mice brains. ${ }^{42}$ The pro-inflammatory activities of TWEAK tend alter BBB permeability by promoting cytokine 
secretion. ${ }^{38,39}$ Considering the increased permeability of the BBB in schizophrenia, ${ }^{43,44}$ our finding of increased TWEAK levels in schizophrenia patients is quite interesting. We suggest that high TWEAK levels may contribute to the etiopathogenesis of schizophrenia by disrupting the BBB.

The empirical results reported herein should be considered in light of some strengths and limitations. The exclusion of patients with medical conditions, such as major physical/neurological/metabolic/inflammatory diseases, as well as controlling for confounding factors, such as age, sex, BMI and smoking status, can be considered as strengths. However, the study had several limitations. First, its cross-sectional design precludes inferences about causation. Second, the sample size was relatively small, and our findings may not be generalizable to a broader community. It has been found that certain antipsychotics may have immunosuppressive effects and can alter cytokine levels. ${ }^{45}$ Our schizophrenia group used different types of antipsychotic drugs; it would have been safer if a more homogenized sample had been used to avoid the conflicting effects of these drugs. Preclinical data show that gut dysbiosis/permeability is linked to increased TWEAK levels, ${ }^{46}$ and the gut has been associated with stresslinked symptoms of schizophrenia. ${ }^{47}$ Studies have also shown that gut permeability markers are linked to psychiatric disorders. ${ }^{48,49}$ Thus, a further limitation in our study was that we did not evaluate gut dysbiosis/permeability, which could have affected TWEAK levels. This could be a relevant confounding factor that should be considered in future research. Finally, we did not look for other antiinflammatory markers in addition to TWEAK.

Elevated concentrations of serum TWEAK could suggest inflammation, proapoptotic activation, or impaired neurodegeneration in patients with schizophrenia. Given its detectable serum concentration, TWEAK could be a biomarker for schizophrenia and it should be assessed in a cohort study and/or clinical trials.

\section{Acknowledgements}

The authors would like to thank all patients and controls for participating in this study.

\section{Disclosure}

The authors report no conflicts of interest.

\section{References}

1 McGrath J, Saha S, Chant D, Welham J. Schizophrenia: a concise overview of Incidence, prevalence, and mortality. Epidemiol Rev. 2008;30:67-76.

2 Jablensky A. The diagnostic concept of schizophrenia: its history, evolution, and future prospects. Dialogues Clin Neurosci. 2010;12: 271-87.

3 Knapp M, Mangalore R, Simon J. The global costs of schizophrenia. Schizophr Bull. 2004;30:279-93.

4 Howes OD, Fusar-Poli P, Bloomfield M, Selvaraj S, McGuire P. From the prodrome to chronic schizophrenia: the neurobiology underlying psychotic symptoms and cognitive impairments. Curr Pharm Des. 2012;18:459-65.
5 Lewis DA, Gonzalez-Burgos G. Pathophysiologically based treatment interventions in schizophrenia. Nat Med. 2006;12:1016-22.

6 Kirkpatrick B, Miller BJ. Inflammation and schizophrenia. Schizophr Bull. 2013;39:1174-9.

7 Keller WR, Kum LM, Wehring HJ, Koola MM, Buchanan RW, Kelly DL. A review of anti-inflammatory agents for symptoms of schizophrenia. J Psychopharmacol. 2013;27:337-42.

8 Tomasik J, Rahmoune H, Guest PC, Bahn S. Neuroimmune biomarkers in schizophrenia. Schizophr Res. 2016;176:3-13.

9 Eaton WW, Byrne M, Ewald H, Mors O, Chen CY, Agerbo E, et al. Association of schizophrenia and autoimmune diseases: linkage of Danish national registers. Am J Psychiatry. 2006;163:521-8.

10 Miller BJ, Buckley P, Seabolt W, Mellor A, Kirkpatrick B. Meta-analysis of cytokine alterations in schizophrenia: clinical status and antipsychotic effects. Biol Psychiatry. 2011;70:663-71.

11 Potvin S, Stip E, Sepehry AA, Gendron A, Bah R, Kouassi E. Inflammatory cytokine alterations in schizophrenia: a systematic quantitative review. Biol Psychiatry. 2008;63:801-8.

12 Yepes M. TWEAK and the central nervous system. Mol. Neurobiol. 2007;35:255-65.

13 Chicheportiche Y, Bourdon PR, Xu H, Hsu YM, Scott H, Hession C, et al. TWEAK, a new secreted ligand in the tumor necrosis factor family that weakly induces apoptosis. J Biol Chem. 1997;272: 32401-10.

14 Jakubowski A, Ambrose C, Parr M, Lincecum JM, Wang MZ, Zheng TS, et al. TWEAK induces liver progenitor cell proliferation. J Clin Invest. 2005;115:2330-40.

15 Arana JA, Seher A, Neumann M, Lang I, Siegmund D, Wajant H. TNF receptor-associated factor 1 is a major target of soluble TWEAK. Front Immunol. 2014;5:63.

16 Maecker H, Varfolomeev E, Kischkel F, Lawrence D, LeBlanc H, Lee $W$, et al. TWEAK attenuates the transition from innate to adaptive immunity. Cell. 2005;123:931-44.

17 Taniguchi T, Asano Y, Akamata K, Noda S, Masui Y, Yamada D, et al. Serum levels of galectin-3: possible association with fibrosis, aberrant angiogenesis, and immune activation in patients with systemic sclerosis. J Rheumatol. 2012;39:539-44.

18 Park MC, Chung SJ, Park YB, Lee SK. Relationship of serum TWEAK level to cytokine level, disease activity, and response to antiTNF treatment in patients with rheumatoid arthritis. Scand J Rheumatol. 2008;37:173-8.

19 Reyes-Martínez F, Pérez-Navarro M, Rodríguez-Matías A, SotoAbraham V, Gutierrez-Reyes G, Medina-Avila Z, et al. Assessment of urinary TWEAK levels in Mexican patients with untreated lupus nephritis: an exploratory study. Nefrologia. 2018;38:152-60.

20 Desplat-Jégo S, Varriale S, Creidy R, Terra R, Bernard D, Khrestchatisky $M$, et al. TWEAK is expressed by glial cells, induces astrocyte proliferation and increases EAE severity. J Neuroimmunol. 2002;133:116-23.

21 Desplat-Jego S, Feuillet L, Creidy R, Malikova I, Rance R, Khrestchatisky $\mathrm{M}$, et al. TWEAK is expressed at the cell surface of monocytes during multiple sclerosis. J Leukoc Biol. 2008;85:132-5.

22 Mustafa S, Martin HL, Burkly L, Costa A, Martins ML, Schwaninger $\mathrm{M}$, et al. The role of TWEAK/Fn14 signaling in the MPTP-model of Parkinson's disease. Neuroscience. 2016;319:116-22.

23 Barbosa IG, Vaz GN, Rocha NP, Machado-Vieira R, Ventura MR, Huguet RB, et al. Plasma levels of tumor necrosis factor superfamily molecules are Increased in bipolar disorder. Clin Psychopharmacol Neurosci. 2017;15:269-75.

24 Yirün MC, Yirün O, Ünal K, Yüksel RN, Altunsoy N, Yaylaci ET, et al. Serum TNF-related weak inducer of apoptosis (TWEAK) and TNFrelated apoptosis-inducing ligand (TRAIL) levels of patients with bipolar disorder in manic episode, in remission and healthy controls. Psychiatry Res. 2017;257:338-45.

25 Levandowski ML, Viola TW, Wearick-Silva LE, Wieck A, Tractenberg $S G$, Brietzke E, et al. Early life stress and tumor necrosis factor superfamily in crack cocaine withdrawal. J Psychiatr Res. 2014; 53:180-6.

26 Schmidt FM, Koch J, Nowak C, Holdt LM, Teupser D, Hegerl U, et al. Ligands and receptors of the TNF superfamily are decreased in major depression and during early antidepressant therapy. J Psychiatr Res. 2019;119:116-21. 
27 Yaylaci ET, Yüksel RN, Ünal K, Altunsoy N, Cingi M, Şahiner ŞY, et al. TNF-related weak inducer of apoptosis (TWEAK) levels in schizophrenia. Psychiatry Res. 2015;229:755-9.

28 Upthegrove R, Khandaker GM. Cytokines, oxidative stress and cellular markers of Inflammation in schizophrenia. Curr Top Behav Neurosci. 2020;44:49-66.

29 Andreasen NC. Methods for assessing positive and negative symptoms. Mod Probl Pharmacopsychiatry. 1990;24:73-88.

30 Erkoç Ş, Arkonac O, Atakı C, Özmen E. Pozitif semptomları değerlendirme ölçeğinin güvenilirliği ve geçerliliği. Dusunen Adam. 1991;4:20-4.

31 Kostakoğlu AE, Batur S, Tiryaki A, Göğüş A. Negatif semptomları değerlendirme ölçeğinin güvenilirliği ve geçerliliği. Dusunen Adam. 1991;4:16-9.

32 Khandaker GM, Cousins L, Deakin J, Lennox BR, Yolken R, Jones PB. Inflammation and immunity in schizophrenia: implications for pathophysiology and treatment. Lancet Psychiatry. 2015;2:258-70.

33 Serafini B, Magliozzi R, Rosicarelli B, Reynolds R, Zheng TS, Aloisi F. Expression of TWEAK and its receptor Fn14 in the multiple sclerosis brain: implications for inflammatory tissue injury. J Neuropathol Exp Neurol. 2008;67:1137-48.

34 Haack M, Hinze-Selch D, Fenzel T, Kraus T, Kühn M, Schuld A, et al. Plasma levels of cytokines and soluble cytokine receptors in psychiatric patients upon hospital admission: effects of confounding factors and diagnosis. J Psychiatr Res. 1999;33:407-18.

35 Katsuki A, Sumida Y, Murashima S, Murata K, Takarada Y, Ito K, et al. Serum levels of tumor necrosis factor- $\alpha$ are increased in obese patients with noninsulin-dependent diabetes mellitus. J Clin Endocrinol Metab. 1998;83:859-62.

36 Roubenoff R, Harris TB, Abad LW, Wilson PW, Dallal GE, Dinarello CA. Monocyte cytokine production in an elderly population: effect of age and Inflammation. J Gerontol A Biol Sci Med Sci. 1998;53:M20-6.

37 Momtazmanesh S, Zare-Shahabadi A, Rezaei N. Cytokine alterations in schizophrenia: an updated review. Front Psychiatry. 2019; 10:892.

38 Stock AD, Wen J, Putterman C. Neuropsychiatric lupus, the blood brain barrier, and the TWEAK/Fn14 pathway. Front Immunol. 2013;4:484.

39 Stephan D, Sbai O, Wen J, Couraud PO, Putterman C, Khrestchatisky $\mathrm{M}$, et al. TWEAK/Fn14 pathway modulates properties of a human microvascular endothelial cell model of blood brain barrier. $\mathrm{J}$ Neuroinflammation. 2013;10:9.

40 Maarouf A, Stephan D, Ranjeva MP, Ranjeva JP, Pelletier J, Audoin $B$, et al. High levels of serum soluble TWEAK are associated with neuroinflammation during multiple sclerosis. J Transl Med. 2019; 17:51.

41 Saas P, Boucraut J, Walker PR, Quiquerez AL, Billot M, DesplatJego $S$, et al. TWEAK stimulation of astrocytes and the proinflammatory consequences. Glia. 2000;32:102-7.

42 Polavarapu R, Gongora MC, Winkles JA, Yepes M. Tumor necrosis factor-like weak Inducer of apoptosis Increases the permeability of the neurovascular unit through nuclear factor-Kappa B pathway activation. J Neurosci. 2005;25:10094-100.

43 Greene C, Kealy J, Humphries MM, Gong Y, Hou J, Hudson N, et al. Dose-dependent expression of claudin-5 is a modifying factor in schizophrenia. Mol Psychiatry. 2018;23:2156-66.

44 Maes M, Sirivichayakul S, Kanchanatawan B, Vodjani A. Breakdown of the paracellular tight and adherens junctions in the gut and blood brain barrier and damage to the vascular barrier in patients with deficit schizophrenia. Neurotox Res. 2019;36:306-22.

45 de Witte L, Tomasik J, Schwarz E, Guest PC, Rahmoune H, Kahn RS, et al. Cytokine alterations in first-episode schizophrenia patients before and after antipsychotic treatment. Schizophr Res. 2014;154: 23-9.

46 Wang F, Sun NN, Li LL, Zhu WW, Xiu J, Shen Y, et al. Hepatic progenitor cell activation is induced by the depletion of the gut microbiome in mice. Microbiologyopen. 2019;8:e873.

47 Kanchanatawan B, Sirivichayakul S, Thika S, Ruxrungtham K, Carvalho $A F$, Geffard M, et al. Physio-somatic symptoms in schizophrenia: association with depression, anxiety, neurocognitive deficits and the tryptophan catabolite pathway. Metab Brain Dis. 2017;32: 1003-16.

48 Kılıç F, Işık Ü, Demirdaş A, Doğuç DK, Bozkurt M. Serum zonulin and claudin-5 levels in patients with bipolar disorder. J Affect Disord. 2020;266:37-42.

49 Işık Ü, Avşar PA, Aktepe E, Doğuç DK, Kılıç F, Büyükbayram Hi. Serum zonulin and claudin-5 levels in children with obsessive-compulsive disorder. Nord J Psychiatry. 2020;74:346-51. 